¿Dónde se escucha tango en la ciudad de Buenos Aires? Una grografía de los lugares del tango

\title{
¿Dónde se escucha tango en la Ciudad de Buenos Aires?
}

\author{
Una geografia de los lugares del tango \\ Facundo Fernández \\ facu_fernandez_2006@hotmail.com \\ Universidad del Salvador (USAL).
}

\section{Resumen}

Problematizar lo que acontece en un concierto de tango es reconstruir las relaciones que establecen las personas y los objetos desde una dimensión musical y social. A partir de la noción de concierto, se realiza una geografía de los lugares del tango donde actúan los grupos del género. En la primera década del siglo XXI, el circuito de tango porteño ha mutado para configurarse de forma híbrida e integrada por dos flujos de circulación diferenciados pero vinculantes: uno concentrado y otro autogestivo. Cada uno con sus respectivos mediadores, estos lugares dan fuerza al género en la ciudad porteña.

\section{Palabras Clave}

Tango, autogestión, mediación, concierto, Hennion. 


\title{
Where do you hear tango in the City of Buenos Aires? \\ A geography of tango places
}

\begin{abstract}
To problematise what happened in a tango concert is to rebuild the relationships established by people and objects from a musical and social dimension. From the notion of concert, a geography of the places of tango where the groups of the genre perform is performed. In the first decade of the 21 st century the Buenos Aires tango circuit has mutated to be configured hybridly and composed of two distinct but binding circulation flows: one legitimate and one self-suggestive. Each with their respective mediators, these places give strength to the genre in the city of Buenos Aires.
\end{abstract}

\section{Key Words}

Tango, self-management, mediation, concert, Hennion

\section{Introducción}

Según la historiadora Alison Latham (2008), la palabra «concierto» deriva del latín concertare, y significa discutir, trabajar en común, acordar o conjuntar. La noción tiene dos sentidos: la italiana concerto se refiere a unapieza musical para uno o más solistas y orquesta, y la inglesa concert, alude a la interpretación de una música para su público. Como plantea Tía DeNora (2003), la interpretación musical que hace el músico sobre el escenario no se puede separar de la audiencia que la escucha: todo acontece en un mismo momento. El concierto es un objeto de estudio complejo, donde acontece la música a partir de un conjunto de mediadores que lo hacen posible. Ellos son entidades (personas y objetos) con capacidad de agencia que se encuentran en igualdad de condiciones, e inscriptos en una red desde la cual puedenestablecer, modificar o interrumpir sus relaciones (Hennion, 2002). En un concierto de música, ellos vivencian y posibilitan la ejecución dinámica de una melodía, sin estar por fuera del fenómeno. De esta manera, el recinto, los músicos, los fanáticos, los instrumentos, las consolas de sonido, las butacas, las parrillas de luces, 
los acomodadores, los guardias de seguridad, las entradas, los sonidos, etc., se relacionan en una situación concreta a fin de producir el fenómeno de la música.

En la Ciudad Autónoma de Buenos Aires, a finales de la década de los 80 y principios de los 90, la apertura de nuevos espacios de enseñanza públicos conlleva un aumento de la representación de los conciertos de tango. En un ambiente de globalización y neoliberalismo, a principios del siglo XXI, surgen nuevas propuestas musicales juvenilesque, según la antropóloga Victoria Polti (2016), establecen nuevos diálogos estilísticos, con figuras tangueras como Osvaldo Pugliese, Astor Piazzolla, JuanD'Arienzo o Julio De Caro, y grupos de rock, jazz o electrónica. En este contexto, se forma un circuito tanguero híbrido ${ }^{1}$, donde emergen nuevos mediadores. El circuito está compuesto por dos flujos de circulación: (1) el concentrado, que se publicita en medios de comunicación de masas, y se representa en tanguerías, teatros y festivales a los que asiste público de alto poder adquisitivo de procedencia extranjera; y (2) el autogestivo, que se difunde en medios de comunicación nacionales, locales y online, y se interpreta en espacios culturales independientes neocontestatarios, neonacionalistas y neobarriales (Semán, 2005 y Alabarces, 2008), que evocan en sus asistentes de sectores medios un mundo imaginario de solidaridad y cooperación intergeneracional donde la música es una excusa al encuentro que sustenta socialidad.

\section{La forma musical del concierto de tango}

En la escena tanguera de principios del siglo XXI en la Ciudad Autónoma de Buenos Aires, coexisten cuatro tipos de estéticasde concierto.

La forma académica instrumental la interpretan grupos aislados que reutilizan, creativamente, recursos compositivos de figuras del tango. El musicólogo Omar García Brunelli (2019) analiza las composiciones de Diego Schissi y Edgardo Rodríguez, y concluye que mantienen una estructura de cámara, típica de las composiciones de Astor Piazzolla. El disco Tangos Improbables (2010) de Diego Schissi emplea el ritmo aditivo y lo agrupa de forma 3-2-3 para colaborar con la trama de contratiempos que se superponen. Las melodías de sus composiciones son recurrentes. Algo similar sucede con la ejecución del tema Naranjo en flor de Edgardo Rodríguez, que respeta la melodía original de Homero Expósito, pero añade un acompañamiento rítmico de dos compases que se superponen al bajo en cuatro tiempos del piano, y al ritmo sincopado 3-3-2 del contrabajo.

La forma académica electrónica es la denominación elegida para definir el estilo adoptado por grupos de tango electrónico, como Gotan Project, Narcotango, Bajofondo, Tanghetto, San Telmo Lounge y Ultratango. Según los musicólogos María Emilia Greco y Rubén López Cano (2014), estas agrupaciones fusionan di- 
versos géneros musicales como el tango, la música electrónica, el hiphop, el rock, el jazz, la chacarera y el malambo. En sus temas musicales utilizan secuencias repetidas, atmósferas electrónicas estáticas y laxas, técnicas como el scratching y el turntablism, patrones armónicos reiterativos, líneas melódicas poco definidas, bases de hiphop, sampleos (sobre fragmentos de discursos políticos, crónicas de fútbol, frases de tangueros y otras figuras intelectuales argentinas), y uso melódico del bandoneón. Según el músico Lautaro Díaz Geromet (2011) y la musicóloga Ana María Vidal (2007), estas agrupaciones retoman partes de las composiciones de Piazzolla al utilizar recursos reiterativos, fórmulas simples y un lenguaje redundante, que ayuda en la mezcla. Por ejemplo, el tema del marplatense Buenos Aires hora cero, reversionado por San Telmo Lounge, sustituye los ruidos de los instrumentos del tema original por grabaciones de objetos concretos ecualizados, que simulan los sonidos de la ciudad a la madrugada y, sobre ello, mezclan melodías de guitarras eléctricas reproducidas en reversa, sonidos de relojes que marcan las doce horasy relatos de películas inglesas y de programas televisivos argentinos, como Polémica en el bar. El single Queremos paz de Gotan Project también utiliza recursos parecidos, combinando una melodía de bandoneón de Piazzolla, un fragmento del discurso del Che Guevara y sonidos de aplausos sobre una base electrónica en la cual se superpone un sonido ecualizado del tema Adiós Nonino, y loops de frases del Che Guevara como "queremos paz", "queremos construir una vida mejor para nuestro pueblo" e "independientes".

La forma tanguera ${ }^{2}$ reversionada se caracteriza por reflejar un sonido similar a las formaciones históricas, como se observa en el estilo de orquestas típicas como Gente de Tango, Sans Souci, Juan D’Arienzo, Los Herederos del Compás, La Tanturi y La Andariega (Martínez y Molinari, 2016). Los temas Nueve Puntos de Francisco Canaro, Porteño y bailarín de Carlos Di Sarli o El Tamango de Juan D’Arienzo reversionados por la Orquesta Típica Juan D’Arienzo proponen esquemas rígidos que siguen los moldes de los arreglos originales.

La forma típica contemporánea puede observarse en orquestas típicas como Trío Esquina, La Chicana, Pablo Mainetti, Quinteto El Arranque, Posetti-Bolotín, Cuarteto Almagro, Orquesta Típica Fernández Fierro y 34 Puñaladas (hoy Bombay Bs. As.), que forman parte del colectivo La movida del Tango Joven (Polti, 2016). Estos grupos crean nuevos estilos, arreglos y repertorios, que reforman el tango de la guardia nueva y toman otros esquemas musicales. Según lo planteado por Germán Marcos (2012), a principios del siglo XXI, la Orquesta Típica Fernández Branca funda la Máquina Tanguera para reforzar los lazos comunitarios y solidarios de enseñanza, difusión e impulso de estos grupos. Escriben un manifiesto con las características básicas que deben tener las formaciones: crear obras propias, no utilizar nombres de tangos viejos para sus composiciones, llamarse «orquesta típica», y contar con una formación de no menos de nueve 
integrantes, sin piano electrónico y con tres o más violines o bandoneones. Del colectivo surgen orquestas típicas como La Furca, El Espiante, La Biaba, La Sexta, Camino Negro, La Branquita, La Agustín Guerrero, Imperial y La Fervor de Buenos Aires, aunque la mayoría se disuelve luego de pocos años. La Orquesta Típica Fernández Branca se convierte en la Orquesta Típica Fernández Fierro, que pasa a ser la referencia y el modelo musical de muchas agrupaciones. Según Camila Juárez y Martín Virgili (2012), los primeros conciertos del grupo mantienen la línea tradicional de Osvaldo Pugliese, con un ritmo intenso, contrapuntos rítmicos y sonoridades oscuras y disonantes.

\section{La forma social del concierto de tango}

En las décadas de los 80 y los 90, los espacios de enseñanza del tango se encuentran aislados. Los jóvenes reclaman, ante autoridades escolares, el fortalecimiento de los lazos sociales y musicales con los maestros del género. Según la etnomusicóloga Mercedes Liska (2003), el aprendizaje mixto que consta de asistir a conservatorios y luego a maestros particulares entra en crisis, dado que la oferta de profesores no satisfacela demanda de los alumnos. Plantea que existe una competencia entre estilos compositivos e interpretativos del tango, junto a otros géneros como el rock, el jazz y el folclore, que se reparten a los estudiantes. La propuesta de las autoridades es la apertura de nuevos espacios de enseñanza públicos con la asunción del compromiso social y educativo de ensanchar los vínculos con el tango.

Las entrevistas que hace Teresita Lencina (2011) a Javier Cohen, Gustavo Samela y Fabián Bertero dan cuenta de las trayectorias de estos espacios. La Escuela de MúsicaPopular de Avellaneda (EMPA) se funda en 1986, y tiene como objetivo estructurar la formación del tango, el jazz y el folclore. Para formular los programas curriculares del tango se convoca a los músicos Rodolfo Mederos, Aníbal Arias y Horacio Salgán. A lo largo de treinta años, pasan por sus aulas músicos de tango actuales, como Julián Peralta y Hernán y Sonia Posetti. Las materias Música Popular y Tango en la Facultad de Artes de la Universidad Nacional de la Plata (UNLP), forman parte de la enseñanza troncal en las carreras con orientación Piano, Guitarra, Dirección Orquestal, Dirección Coral, Composición y Educación Musical. En el 2008, se crea la carrera de Música Popular, cuyos programas curriculares unifican la enseñanza del jazz y del tango. La carrera de Folklore y Tango en el Conservatorio Superior de Música Manuel de Falla se funda en 2003, y toma como modelo la cátedra Ritmos y formas del folclore y la música ciudadana de Juan Falú y Marta Sima. En 2005, se transforma en Profesorado de Música con orientación en Instrumento - Folclore y Tango, con el objetivo de formar de manera integral al músico, con contenidos populares y didácticos. La Escuela 
Orlando Goñi surge en el año 2004 de la mano de Oscar Fischer, Julián Peralta y otros músicos, con el objetivo de generar un espacio colectivo de capacitación en el manejo técnico de la música, la gestión y el sostenimiento de proyectos. El docente-investigador Daniel Gonnet (2017) describe que la institución divide clases de instrumentos (bandoneón, violín, viola, violonchelo, guitarra, flauta, piano, contrabajo ypercusión), de arreglos y de ensamble, conteniendo materias como Lenguaje Musical, Práctica de Orquesta, Análisis, Orquestación y Composición. Los investigadores en música Aude Bresson y Daniel Gonnet (2018), en su autoetnografía, desarrollan la forma de enseñanza de este espacio: los alumnos incorporan los conocimientos musicales básicos, con el propósito de perder el miedo a tocar frente a un público; para cumplir esta meta, forman grupos musicales junto a un músico-docente, que oficia de director, y realizan pruebas y actividades interpretativas mediante las que incorporan las marcaciones y los gestos del género, sin penalizar la equivocación; los maestros incentivan a los estudiantes a crear arreglos y composiciones propias, y a tocar sin partitura, como un bloque; cuando los estudiantes han aprendido los rudimentos básicos del género, se incorporan al mercado laboral, debiendo conseguir fechas para tocaren los espacios de música. La escuela es un «semillero» de grupos actuales del género, como Alto bondi, El cachivache, Contragolpe, Chifladas, Juega que llega, La brecha, La Hoguera, Quinteto Criollo González Calo, Sobrepique, Zitarrosur, y orquestas como la Andariega, Cambio de Frente, Ciudad Baigón, la Carmen y la Julián Peralta.

Las cuatro instituciones anteriores suministran intérpretes y compositores al circuito del tango. A partir de este contexto, la etnomusicóloga Jennie Gubner (2014) plantea la existencia de dos circuitos de circulación y consumo. El "for export" (Gubner, 2014, p. 127) genera propuestas tangueras de baile y música hegemónicos que son financiadas por grandes grupos económicos y se ofrecen a turistas. El "not for export" u "off" (p. 128), compuesto de proyectos musicales y bailables subalternos o de menor reconocimiento, costeados por pequeños productores y dirigidos a la clase media. A diferencia de esta interpretación, se postula aquí que existe un circuito híbrido compuesto por un conjunto heterogéneo de lugares cuyos mediadores ofrecen programas musicales y bailables, más o menos mixtos. La conceptualización que se propone en esta investigación integra, desde espacios que presentan espectáculos de tango de manera constante hasta lugares donde estas exhibiciones son esporádicas. El circuito híbrido se diferencia en dos flujos dinámicos donde actores y objetos se entrecruzan: uno concentrado y otro autogestivo.

\section{El flujo de tango concentrado}

El flujo concentrado tiene lugar en tanguerías, teatros y festivales masivos situa- 
dos en la Capital Federal (Salton, 2019; Calello, 2017; Cecconi, 2018). Este impulso del género se produce en la década del 90 por un conjunto de políticas públicas que promueven lo que el antropólogo Carlos Hernán Morel (2009) define como la patrimonialización del tango. En 1990, es promulgado, a nivel nacional, el Decreto Presidencial N. 1235, cuyo objetivo es la recopilación, el ordenamiento, el estudio y la salvaguarda del patrimonio artístico nacional. En 1996, se sanciona la Ley Nacional del Tango N. 24.684, mediante la cual se protege la danza, música y letra del tango. A partir del 2001, el baile se convierte en una propuesta atractiva para turistas deseosos de gastar dólares en este circuito del género y bailar el tan ansiado tango. En 2004, se crea la Academia de Estilos de Tango Argentinos (ACETA) y un Programa de Ballet Escuela de Tango, que forma a jóvenes en la danza. Como producto del éxito del género, en la Ciudad de Buenos Aires se abren otros espacios como el Centro Educativo del Tango (CETBA), la Orquesta Escuela de Tango, el museo Casa Carlos Gardel y el Ballet de Tango para fomentar la cultura del género. Estas políticas públicas, junto a la declaración de la Organización de las Naciones Unidas para la Educación, la Ciencia y la Cultura (UNESCO) del tango como Patrimonio Cultural Inmaterial de la Humanidad de Uruguay y Argentina, ponen en valor el género en los aglomerados urbanos de la Capital Federal, con una gran concentración de capital económico ${ }^{3}$. Con este apoyo se estabilizan en el flujo diferentes mediadores como empresarios, mozos, chefs, organizadores, ticketeadoras, bailarines, instrumentos, agencias de turismo, hoteles, coreógrafos, luces, telones, acomodadores, productoras, sonidistas, editores, músicos, computadoras, equipos de sonido, público, mesas, butacas, planillas de programación, boletos, limpiadores y agentes de seguridad que impulsan programas musicales y bailables de tango - espectáculo cuyo repertorio es mayoritariamente cosmopolita y tradicional-.

Los lugares del flujo concentrado se encuentran en los barrios del centro porteño. Se logra apreciar una concentración alta (de más de cinco espacios por comuna) en San Telmo, San Nicolás, Monserrat, Puerto Madero, Retiro, Balvanera, San Cristóbal, Almagro, Boedo y La Boca, una media (con un máximo de tres espacios por departamento) en Villa Crespo, Chacarita, Colegiales y Palermo, y una baja (de un recinto por distrito) en Barracas y Nueva Pompeya.

Las tanguerías surgen a principio de 1960 y crecen exponencialmente entre 1970 y 1990, como consecuencia de la puesta en valor de conglomerados habitacionales en el centro de la Capital Federal. El objetivo de esta localización estratégica es la reactivación económica y turística de la historia del tango. El Observatorio de Industrias Culturales de la Ciudad de Buenos Aires, en su informe anual de 2007 titulado El tango en la Economía de la Ciudad de Buenos Aires, contabiliza un total de cuarenta tanguerías, entre las cuales se nombran a Taconeando, El Viejo Almacén, La Esquina Homero Manzi, Bar Sur, Caminito Tango Show, Cátulo tango, El 
Café de los Angelitos, La Esquina Carlos Gardel, Señor Tango, Madero Tango y Tango Porteño. Las actividades que ofrecen constan de una cena-baile-show. Los espectadores, mayormente extranjeros, asisten a una comida y a un espectáculo de baile conducidos por un narrador que cuenta la historia del género. Cecconi (2018) diferencia las tanguerías en tres clases según el tamaño del recinto, el show propuesto y el menú ofrecido. Las de clase A tienen la capacidad de albergar en su interior a más de ochocientas personas y brindan cualquier servicio gastronómico, apuntan a captar turistas de clase alta o personas de negocios, alojados/as en hoteles cercanos, y el precio final de la noche ronda los USD300. Estos sitios tienen convenios con agencias de turismonacionales y lugares de alojamiento, como la cadena hotelera NH. Las de clase B dan lugar a ochocientos comensales y ofrecen el conjunto de cena-show a un precio inferior a los USD300, valor que se ajusta a la categoría del lugar, la ubicación de la mesa y las características de la cena; asisten turistas que gastan de manera ostentosa o extranjeros que lo hacen de forma discreta. Las de clase $\mathrm{C}$ brindan un espectáculo económico y un servicio de lunch para ciento veinte personas.

El tango en los teatros del circuito comercial y oficial porteño resurge en 1992, con el éxito del espectáculo Tango Argentino, presentado en el Teatro Gran Rex y en el Lola Membrives. A principios de siglo XXI, exhiben unipersonales de música o baile que buscan resaltar el papel de los intérpretes o bailarines. En los teatros comerciales de la calle Corrientes (Spinella, 2012), se observan espectáculos como Tanguera del productor Diego Romay, que presenta en escena a veintitrés bailarines, entre los cuales se encuentran Mora Godoy, María Nieves, Marianella, Antonio Junior Cervila, Marcelo Testa y Esteban Dominichini (Calello, 2017). Desde el año 2010, estas actividades se multiplican porque comienzan a ser rentables. Mora Godoy protagoniza Chantecler Tango (2014), en el Teatro Opera Allianz, Bailando tango remix (2016), en el Teatro Maipo, y Calles de tango (2019), en el Teatro Astral; Alejandra Gutty interpreta Calles de tango (2019), sobre la calle Corrientes, y Natalia Hills actúa en Romper el piso (2012). El circuito oficial, integrado por el Teatro Colón y el Complejo Teatral de Buenos Aires (CTBA) ofrece, mayoritariamente, conciertos instrumentales y, minoritariamente, espectáculos de baile. En el año 2011, se presentan en el Teatro Colón Rodolfo Mederos, Adriana Varela y Gerardo Gandini junto a la Orquesta Filarmónica de Buenos Aires, como también El café de los maestros y la Selección Nacional de Tango. A su vez, entre los años 2011 y 2018, la Orquesta de Tango de la Ciudad de Buenos Aires se presenta en los teatros San Martín, Regio y Presidente Alvear, para homenajear a intérpretes, compositores y letristas del género (Peña, 2006). En menor proporción, se presentan en el Teatro Colón los tangos clásicos El último café, de Cátulo Castillo y Héctor Stampone, y Romance del diablo, de Astor Piazzolla, bailados por Julio Bocca y Ceci- 
lia Figaredo para festejar el aniversario de la creación de su Ballet, y el espectáculo Tramatango (2010) de Milena Plebs, en el Teatro Presidente Alvear.

Los festivales de tango masivos son megaeventos culturales estatales que seconcentran en la Ciudad de Buenos Aires, como el Festival BA Tango, el Campeonato Metropolitano de Tango y el Campeonato Mundial de Baile de Tango (Morel, 2009). Según Morel (2013), el primero funciona desde 1998 bajo el nombre de Fiesta Popular del Tango, y es la respuesta a los diversos festivales extranjeros y privados que utilizan al género, como el Festival Bailemos tango y el Festival por el día internacional de la mujer, de la bailarina y coreógrafa Johana Copes, el $8 v 0$. Misterio Tango Festival de la milonga La Viruta, el Festival Cambalache, el Congreso Internacional de Tango Argentino, el Lady's Tango Festival, el CITA, el 3er. Amor Tango Festival, la 5ta. Menesunda Tango Festival, el Tango Canyengue Week y el Festival Nacional de Tango Carlos Gardel. La fiesta cambia su nombre a Festival Buenos Aires Tango con el éxito de las primeras ediciones y amplía a cuarenta sus sedes en la Capital Federal. Se realizaen plazas, clubes, salones, centros culturales y milongas, y en recintos masivos, como los estadios Obras Sanitarias y Luna Park, y el predio de La Rural. El tango se consolida como la marca nacional y afecta los balances públicos de las carteras de cultura de Jefes de Gobierno como Aníbal Ibarra, Jorge Telermann, Mauricio Macri y Horacio Rodríguez Larreta. El festival es tan relevante que grupos políticos y económicos se disputan la definición de las fechas de realización de las ediciones posteriores. Es trasladado del 11 de diciembre, Día Nacional del Tango, a los primeros días de febrero y marzo, para coincidir con el carnaval e influenciar a la industria turística nacional e internacional. Desde 2002, las actividades se concentran en el baile y no tanto en la música. Se promueve el Campeonato Metropolitano de Tango en el mes de agosto y, luego, se unifica con el Campeonato Mundial de Baile, que premia a parejas de baile de tango salón y tango escenario. Para el año 2010 se reduce la cantidad de sedes a nueve. En la edición de 2019 se abren lugares en las zonas de concentración alta, mientras que en 2020 se realiza vía streaming, entre el 26 y 30 de agosto, a consecuencia de la pandemia del virus Covid-19. La cuenta Festivales BA del Gobierno de la Ciudad de Buenos Aires publica videos en YouTube, cuyo contenido tiene pocas reproducciones sise tiene en cuenta la diversidad de propuestas que se presentan, desde filmaciones didácticas para niños, clases de baile online, milongas virtuales y exhibiciones de parejasen el mundial de tango.

El flujo concentrado es publicitado por la prensa escrita y el cine. Según la comunicadora social Jimena Jáuregui, en su artículo Imágenes y sólidos del tango en movimiento. Las orquestas en el cine documental (2016), se producen ficciones odocumentales autobiográficos de figuras de renombre, como Yo no sé qué me han hecho tus ojos (2003) de Sergio Wolf y Lorena Muñoz sobre Ada Falcón, Pichuco (2014) de Martín Turnes sobre Aníbal Troilo, Tango en París, recuerdos de Astor Piazzolla (2017) de Rodrigo Vila sobre la actividad del compositor marplatense, y Un tango más 
(2015) de Germán Kral sobre María Nieves Rego y Juan Carlos Copes. Otros films retratan el vínculo entre el baile del tango y la danza clásica y/o ballet. La ficción Tango Your Life(2012) de Chan Park, Her tango (2017) de Jason Mullis, y Another tango (2018) de Sean Beyer muestran relatos simples, que ponen el acento en el baile como elemento movilizador de la trama. Otras producciones reflejan el carácter nómade del tango en Finlandia, como Prisoners of the ground (2009) de Stella Van Voorst Beest, Tango de una noche de verano (2013) de Viviane Blumenschein, y Tango suomi (2016) de Gabriela Aparici, y en Canadá, como Hearts of Tango. A close embrace of life (2014) deMiguel Libedinsky. Los medios masivos de comunicación, como Clarín y La Nación, publicitan los espectáculos de tango unipersonal y los festivales masivos en sus respectivas secciones de cultura o espectáculos.

\section{El flujo de tango autogestivo}

Los cambios sociales, políticos, económicos y culturales, producidos por la crisis del 2001, generan el desmembramiento de las relaciones sociales de los sectores populares respecto de su sentido de pertenencia local. Las actividades de entretenimiento y consumo cultural son disminuidas en cantidad por la tragedia de Cromañón (2004), que ocasiona la clausura de espacios culturales que no cumplen con las normas de seguridad necesarias para evitar nuevos incidentes (Wortman, 2015; Cervellera, 2019).

Como consecuencia, surgen en barrios céntricos de la Capital Federal, como Palermo, Belgrano y Almagro, nuevos espacios denominados centros culturales, que abogan por una relación particular con la cultura como derecho y no como ocio. Así, ofrecen experiencias de ocio creativo, donde el placer y el displacer se relacionan a travésde las dimensiones de lo cultural (lúdica, creativa, festiva, ambiental-ecológica y solidaria), proponiendo al sujeto una participación activa a fin de que pueda hacer algo con lo que se le presenta. A estos lugares acuden individuos o colectivos de sectores medios o populares, tales como militantes, desocupados, universitarios y movimientos sociales. Con el paso del tiempo, estos espacios establecen cuatro tipos de perfiles: (1) lugares como la Casa Abasto funcionan como micro-emprendimientos individuales, con talleres de formación profesional para aquellas personas que encuentran vulnerado su derecho de acceso al trabajo; (2) recintos como el Centro de Ideas y programa de radio autogestionado Mate Amargo, o el Centro Cultural Todesca, que piensan a la cultura como una toma de posición política y hacen ciclos de cine, cursos de formación y debates sobrela realidad política nacional; (3) sitios como el Centro Cultural La Vereda o el Centro Cultural El Barrio, que contienen de manera profesional a personas afectadas por la crisis; y (4) espacios como La Casona de Humahuaca, el Centro Cultural La Sala o el Centro Cultural La Kasa de las Estrellas, que promueven formas artísticas 
alternativas y experimentales, y apuntan a despertar nuevas sensibilidades o estilos de vida con sus actividades de formación, talleres, música en vivo, teatro y fiestas.

En 2014, con el impulso de estos sectores, se crea el Movimiento de Espacios Culturales y Artísticos (MECA), que nuclea a más de cuarenta centros culturales de la Capital Federal para defender y recuperar los espacios colectivos, cooperativos y políticos perdidos, movimiento que es impulsor, ese mismo año, de la Ley $\mathrm{N}$. 5240 de Centros Culturales, que logra reglamentarlos de la siguiente manera: "espacio no convencional y/o experimental y/o multifuncional en el que se realicen manifestaciones artísticas de cualquiera tipología que signifiquen espectáculos, funciones, festivales, bailes, exposiciones, instalaciones y/o muestras con participación directa o tácita de los intérpretes y/o asistentes" (Cervellera, 2019, p. 5).

Hasta 2018, los centros culturales se expanden e incluyen a nuevas expresiones que abogan por la reformulación de la ley. En ese año se crea la Ley N. 6063 de EspaciosCulturales Independientes que los define como:

...establecimiento con una capacidad máxima para trescientos asistentes y una superficie máxima de quinientos metros cuadrados de superficie cubierta en el que se realicen exposiciones de arte, proyecciones audiovisuales y de multimedia, radio digital, manifestaciones artísticas con participación real y directa de creativos y artistas y todas las actividades autorizadas para los Teatros Independientes, Peñas, Milongas, Clubes de Música en Vivo y Centros Culturales (Ley N. 6063, 2018, p. 1).

Aquí se realizan ensayos, seminarios, charlas, talleres, clases o actividades formativas del arte y la cultura, como también la venta de bebidas, alimentos y artículos culturales en sectores de café-bar, restaurantes, librerías, disquerías, galerías de arte, salones de exposición, conferencias, estudios profesionales, clubes de barrio y otros. Astillero, a lo largo de su trayectoria, elige presentarse en estos espacios culturales independientes con el fin de apoyar su difusión.

El flujo de tango autogestivo se compone mayoritariamente de centros culturales, clubes de música en vivo, teatros independientes, festivales autogestivos y, minoritariamente, de milongas tradicionales y milongas modernas (electrónicas, queer y colectivas). Estos sitios ofrecen programas bailables y musicales híbridos, impulsados por mediadores como pequeños empresarios, grupos autogestivos, movimientos artístico-culturales, artistas-gestores, público, músicos, bailarines, comunicadores individuales, organizaciones barriales, vecinos, mozos, cocineros, mesas, sillas, redes sociales, escenarios, aplicaciones digitales, consolas de sonido e instrumentos. Se opta por identificar estos lugares en las páginas de Facebook e Instagram de los grupos más representativos del sector, debido a las dificultades para encontrar una base de datos quelos recopile. 
Los barrios con mayor densidad de sitios de tango se encuentran en San Nicolás, Montserrat, San Telmo, Puerto Madero, Almagro, Balvanera, Villa Crespo, Palermo y Colegiales, con más de cuatro, seguidos por Retiro, La Boca, San Cristóbal, Boedo, Retiro, Recoleta, Villa Pueyrredón, Villa Ortúzar, Parque Chas y Villa Urquiza, con una concentración media de dos a tres recintos, y por Barracas, Constitución, Caballito, Parque Chacabuco, Flores, Villa Soldati, Núñez y Villa General Mitre, con una concentración baja de un espacio. Es relevante señalar que el flujo autogestivo se esparce por zonas de la Capital Federal y del Conurbano Bonaerense donde solo hay milongas, como los barrios de Caballito, Parque Chacabuco, Flores, Villa General Mitre, Villa Soldati, Villa Urquiza, Villa Pueyrredón, Banfield, Lomas de Zamora, Temperley, Adrogué, Claypole, Avellaneda, Gerli y Vicente López. Mediante una comparación de ambos flujos, se observa que el circuito híbrido tiene una mayor concentración en los barrios de San Nicolás, Montserrat, San Telmo, Puerto Madero, Balvanera, Almagro y Villa Crespo, donde las distancias que separan las distintas propuestas son cortas y van de una a dos cuadras. Se encuentran zonas de concentración media, como San Cristóbal, donde el trayecto que distingue ambos espacios es más largo —una distancia de cinco a quince cuadras-.

Las milongas porteñas son descritas en etnografías realizadas por Carozzi (2015), Verdenelli y Orozco (2009) y Cecconi (2010). Se diferencian entre «tradicionales» y «modernas» según la pertenencia generacional, el estilo de baile utilizado, la estética dellugar y la orientación sexual de los participantes. Las milongas tradicionales aparecen enbarrios como Mataderos, Flores, Villa Urquiza, San Telmo o Montserrat. Aquí asisten tanto jóvenes y viejos milongueros heterosexuales con su pareja o con amigos. Los mayores tienen la reputación de ser buenos bailarines. Las mujeres ansían bailar con ellos, aunque tienen el rol de no poder invitar a nadie. Para lograr que las saquen a bailar, las personas mayores se lucen con otras parejas de menor fama y tratan de llamar la atencióncon su belleza, su habilidad o su suerte. Cuando captan la atención del hombre, este las saca a bailar mediante una frase o un cabeceo, y así las convierte en milonguera. Las posiciones de baile son rígidas, predefinidas y estáticas, en función al género: el hombreguía y la mujer sigue. Los estilos de baile que se aceptan son el del centro, que se caracteriza por un abrazo estrecho y pasos más cortos, y el Urquiza, que elabora una coreografía más elegante, a través de una postura corporal de abrazo abierto y movimientos largos. Los hombres van vestidos de traje, pantalón de vestir, camisa, corbata y zapatos de suela, y las mujeres llevan vestidos de noche, faldas y zapatos con taco alto. La música que se escucha es de orquestas de los años cuarenta y los años cincuenta, como D’Arienzo, Di Sarli, Troilo, Caló, Canaro, Láurenz o De Caro.

Las milongas modernas tienen lugar en clubes porteños, centros culturales, bares o pubs, de los barrios de Palermo, Almagro, San Cristóbal, Boedo, Flores, 
Montserrat y Villa Crespo. Los códigos de baile de estos milongueros jóvenes homosexuales, heterosexuales y disidencias, de veinticinco a cuarenta y cinco años, se relacionan con prácticas más abiertas y flexibles. Las mujeres pueden invitar a bailar al hombre, o quedarse en una mesa y conversar con otros grupos. El tipo de tango que practican es el nuevo, que se caracteriza por la combinación con otras danzas modernas. La coreografía necesita de cuerpos flexibles para hacer acrobacias y figuras, movimientos abiertos y un abrazo que puede quebrarse. En el interior de las milongas modernas se diferencian tres propuestas claras: las electrónicas, las queer y las colectivas. Las milongas electrónicas, como La antimilonga y La Marshall, son las primeras en presentar a grupos del género como Otros Aires o San Telmo Lounge. Los códigos corporales de los bailarines se vinculan con formas de erotismo y relaciones de género particulares y no personifican un rol, sino que se prioriza la comunicación para disfrutar del baile. Se ofrecen, de forma esporádica, recitales de tango electrónico con elementos audiovisualesúnicos, como proyecciones de videos con contenido social comprometido y fotografías de la ciudad de Buenos Aires. En la actualidad, los boliches electrónicos integran este estilo de tango. Las milongas queer se caracterizan por cuestionar las prácticas heteronormativas corporales y los roles genéricos. En 2003, abre La Marshall, con la posibilidad de bailar entre varones y elegir el rol que se personifica. Un tiempo después, la bailarina Mariana Docampo crea la milonga Buenos Ayres Club para desdibujar los contornos con otras propuestas heterosexuales. Se promulga un tipo de baile que combinaelementos del canyengue, del nuevo y del salón, y se escuchan desde tangos clásicos de orquestas típicas de los años veinte hasta los años cincuenta, pasando por tangos de actualidad y electrónicos, hasta cortinas de música pop, balada, música popular brasileñay cumbia colombiana. En este espacio se enseña la alternancia de ambos roles, a partir deejercicios que implican cambios de posición para posibilitar la desexualización de losroles genéricos. Se insiste en que cada cuerpo explore los propios movimientos sin naturalizar la práctica, diversificando la experiencia de disfrute y deseo a partir de la multiplicidad de cuerpos a interactuar.

En la primera década del siglo XXI, en barrios de la Capital Federal surgen milongas colectivas, que se caracterizan por ofrecer una programación compuesta por una clase o lección de baile, seguida por un concierto de tango que, en ocasiones, presenta exhibiciones de baile. Algunos de estos sitios abren legalmente como milongas y ofrecenesta propuesta, como la Milonga de Artigas, Zona Tango, Sin Gomina y Abracatango. Enotros, su estatus legal es como bares, centros culturales o pubs, pero presentan espectáculos de milonga, como Amapola en el bar La Paz Arriba, y La Milonga del Tasso, en el Centro Cultural Torquato Tasso. En el momento de la clase de baile, las sillas y las mesas se apilan para dar lugar a la pista pero, cuando se organiza el concierto, todo aquelloes devuelto a su lugar. 
Los hombres visten de manera más casual, con jeans, zapatillas yzapatos de suela, y las mujeres eligen ropas amplias y zapatos de taco. Se presentan grupos locales y barriales, como Derrotas cadenas, Orquesta típica canyengue, Orquesta Típica Cambio de Frente, y más reconocidos, como el Quinteto Criollo González Calo yAstillero.

Los centros culturales y los clubes de música ofrecen conciertos de tango y otras presentaciones escénicas. Algunos recintos, como Pista Urbana, Club Atlético Fernández Fierro (CAFF), Café Vinilo, Bar El Faro, Sanata Bar o Galpón $\mathrm{B}$, ofrecen eventos musicales orientados a jóvenes entre veinticinco y cuarenta y cinco años de edad, pertenecientes a la clase media y media-baja, que pagan una entrada con precios módicos.

Los circuitos del teatro alternativo y off proponen programas literarios, musicales y bailables en salas pequeñas, de aproximadamente cien o ciento cincuenta espectadores.Presentan obras de teatro o espectáculos musicales que cuentan historias alternativas de tango. La obra Giros - una bistoria de tango (2019), en el Espacio Aguirre, relata la historia de una mujer cuya llegada a la milonga desata una lucha de poder con otros personajes. El espectáculo Así se baila el tango (2018) del Portón de Sánchez y el TeatroEnsamble describe, en clave de comedia, una sátira al baile del tango. Las coreografías del colectivo de Trabajadores del Tango - Danza (TTD), como Adiós tango (2018) y Cuenta el tango (2020), en el Teatro Hasta Trilce, presentan una fusión de tango nuevo con otras danzas. Sin embargo, algunos teatros, como el Teatro Orlando Goñi, Monteviejo, El Alambique, el Anfiteatro del Parque Centenario y el Centro Cultural Néstor Kirchner, funcionan como espacios de concierto a los que asisten jóvenes alencuentro de su grupo favorito.

Los festivales de tango barriales surgen aproximadamente en el año 2010, como consecuencia de las demandas políticas de algunos actores colectivos en relación a los problemas del Festival de Tango Buenos Aires. En respuesta a la concentración de las sedes en barrios céntricos, la importancia del baile y la poca representación local y barrial,el Sindicato Argentino de Músicos, el colectivo cultural Quinteto Negro La Boca y la Asociación de Organizadores de Milongas, se unifican para repudiar esta propuesta. En consonancia, grupos encarnados por pequeños empresarios, actores autogestivos, movimientos artístico-culturales y artistas-gestores, promueven festivalesautogestionados, independientes y privados, para responder a las demandas culturales locales y dar visibilidad a grupos regionales. Se crean festivales de tango independientesen Almagro, Luján, San Telmo, Boedo, Parque Patricios, Valentín Alsina, Almirante Brown, Temperley, Chacabuco, La Boca y en el Club Atlético Fernández Fierro. A medida que se afianzan estos eventos, los espacios estatales culturales participan de manera activa. Desde 2011, el Centro Cultural Haroldo Conti, el Espacio Cultural Nuestros Hijos y el Centro Cultural Néstor Kirchner presentan el Festival de Tango y, desde 2014, el Primer Encuentro Internacional 
de Tango para Músicos, donde se brindancharlas, conciertos, conferencias y clases particulares de grupos locales, como la OrquestaAtípica La Empoderada, la Orquesta Típica Siniestra y el Quinteto Negro La Boca, juntoa músicos reconocidos como Gabriela Novaro, Bárbara Grabinski, Ramiro Gallo, DiegoSchissi, Julián Peralta, Juan Pablo Navarro, Exequiel Mantega, Hernán Possetti, Pablo Fraguela, Santiago Segret, Sebastián Henríquez, Eva Wolff, María Elía, Adrián Enríquez, Gustavo Hunt y Paulina Faín. En 2017, se propone el Primer Concurso Internacional deNuevos Ensambles de Tango, donde grupos jóvenes tocan un repertorio propio y son premiados por un jurado compuesto por Julián Peralta, Ramiro Gallo, Diego Schissi, Juan Carlos Cuacci y Gustavo Marguiles. Se declaró como ganador colectivo a cinco grupos: la orquesta Utópica y la Máquina Invisible, de la ciudad de Rosario, el dúo Domínguez-Martinini y la Guardia Nueva, de la Ciudad de Buenos Aires, y el Sexteto Murguier de laCiudad de La Plata. En 2020, como consecuencia de las restricciones de circulación producto de la pandemia por el virus Covid-19 y como respuesta a la propuesta de streaming del Festival de Tango Buenos Aires surge el Festival de Tango Online en el que participan treinta y nueve grupos, entre los que se encuentran Astillero, Orquesta Típica Fernández Fierro, Ramiro Gallo Quinteto, Bombay Buenos Aires, Orquesta Típica Cambio de Frente, QuintetoNegro La Boca y Alto Bondi.

El flujo autogestivo se publicita en medios de comunicación masivos como el cine, la radio, la televisión y las redes sociales. Jáuregui (2016) muestra que hay documentales de producción y coproducción locales, que narran las experiencias de las orquestas del siglo XXI y de las milongas queer. Si sos brujo: una historia de tango (2005) de Caroline Neal, Tango en el Tasso (2013) de Acho Estol, El último aplauso (2009) de Germán Kral, y Los locos de Almagro (2013) de Jennie Gubner cuentan, desde diferentesperspectivas, el pasaje generacional de figuras históricas del tango a jóvenes promesas. El primer largometraje sigue los pasos de Ignacio Varchausky, miembro de la orquesta típica El Arranque, en su peripecia por crear una orquesta escuela junto a Emilio Balcarce,reconocido compositor e intérprete de las década del 50 al 70. La segunda película relatalo acontecido en el Festival de Tango Tasso, al que concurren músicos adultos y jóvenes,como Adriana Varela, Susana Rinaldi, Horacio Salgán, Leopoldo Federico, Sexteto Mayor, Atilio Stampone, la Selección Nacional del tango, Hugo Rivas, Julio Panne, Néstor Marconi, La Chicana, Rodolfo Mederos, Astillero y Lidia Borda. El tercer film describe la historia del pasaje generacional en el bar El chino de los cantores, Cristina delos Ángeles, Inés Arce y Julio César Fernán, a la Orquesta Típica Imperial. La cuarta cinta expone la historia de la orquesta de Juan Pablo Gallardo, y la convocatoria del célebre cantante Osvaldo Peredo para ofrecer conciertos en el Almagro Tango Club y Sonata Bar. Los documentales de Alejandro Diez, Un disparo en la noche (2012) y Un disparo en la noche Vol.2 (2019) relatan, desde la voz de los intérpretes de la Orquesta Típica 
Julián Peralta, la evolución del género en los últimos veinte años. En ambos volúmenes se observa a la orquesta actuar y se puede recorrer la grabación de los temas de ambos discos con comentarios de sus protagonistas. El corto documental Asígrabamos Arcadia (2020) de Alejandro Diez narra la grabación en estudio del último disco de Astillero. El film Remándola en el tren. Un viaje con La Vidú (2014) de Juliette Igier relata la gira de la Orquesta Típica La Vidú a Córdoba, y la película Tango queerido(2016) de Liliana Furió es el primer largometraje documental que relata la experiencia del baile del tango por parte del colectivo LGTBIQ. En cuanto a la radio, nace en 1999 laemisora FM Tango $92.7 \mathrm{MHz}$ (hoy 2X4), que ofrece una línea editorial de escucha de losnuevos grupos del género. Surgen otros diales de frecuencia modulada y de amplitud modulada, como Radio Malena (FM 89.1) y Radio Nacional (AM. 870), y emisoras online como Fractura expuesta y Doble A, que mantienen la misma idea. En 2010 se funda Radio CAFF, para promocionar a estos grupos en su programación habitual, con programas como Rituales Urbanos de Martín Maciel, Corazón de tango de Jürgen y Cristina, Canciones como semillas, de Alfredo "Tape" Rubín, Rock y Tango, de GermánMarcos, Cinco por uno y Vivo en el CAFF. En la televisión, Canal 7 o TV Pública divulgan al género. En 2005, el programa Zarpando tangos, que conducen Guillermo Fernández y Luis Longhi, convoca a grupos del tango contemporáneo. En 2015, la miniserie documental Tango pasión Argentina, de la mano del cantante de la Orquesta Típica Fernández Fierro, Walter "Chino" Laborde, construye una historización del tango hasta el presente. En 2019, La Hora del Tango, con la conducción de Sandra Mihanovich, presenta a orquestas contemporáneas como El Arranque o Color Tango. Todos estos espacios radiales y televisivos utilizan como método de difusión el manejo de sus propias redes sociales, como Facebook e Instagram, donde postean noticias, adelantos y nuevos conciertos del género.

\section{Conclusión}

El concierto de tango como fenómeno socio-musical se encuentra habilitado por diferentes mediadores que permiten su funcionamiento. Estos actores y objetos se asocian de determinada manera para permitir que la música acontezca. En la Ciudad Autónoma de Buenos Aires, ellos dan vida a la música que sucede en teatros, milongas, tanguerías, festivales masivos y autogestivos y espacios culturales independientes. Allí tocan diferentes grupos que representan una forma académica o tanguera en sus diferentes vertientes como la electrónica, la instrumental, la reversionada o la contemporánea. A partir de esta descripción, surgen nuevos interrogantes tales como: ¿cómo se configura el circuito por fuera de la Ciudad de Buenos Aires y el resto del país? O ¿qué otros músicos y compositores complejizan la forma musical del género? 


\section{Notas}

1. La hibridez cultural supone comprender el circuito del tango de una manera integrada y no diferenciada entre gustos populares y cultos. (Radakovich, 2014).

2. La división analítica entre "académica" y "tanguera", surge para diferenciar propuestas musicales que utilizan más recursos de los compositores renovadores o de Osvaldo Pugliese, respectivamente.

3. Como Palermo, Puerto Madero, San Telmo, etc.

\section{Referencias}

Adorni, A. (2018). Sonoridades del tango de hoy. Un análisis de las nuevas composiciones para orquesta típica. En M. Liska y S. Venegas (Coords.) Tango, ventanas del presente II: de la gesta a la historia musical reciente (pp. 9-35). Centro Cultural de la Cooperación Floreal Gorini.

Alabarces, P. (2008). Posludio: Música popular, identidad, resistencia y tanto ruido (para tan poca furia). TRANS. Revista Transcultural de Música, 8(12), 1-13.

Boix, O. (2013). Sellos emergentes en La Plata: nuevas configuraciones de los mundos de la música. [tesis de maestría]. Universidad Nacional de La Plata, Facultad de Humanidades y Ciencias de la Educación.

Boix, O., Gallo, G., Irisarri, V., y Semán, P. (2018). Romanticismo, crítica y uso: los emprendimientos musicales independientes y las discusiones del campo de estudios de la música. El oído pensante. 6(2), 77-99.

Bresson, A., y Gonnet, D. (2018). Circulación, construcción de conocimientos y oficio del músico de tango. La experiencia de la escuela Orlando Goñi. En N. Alessandroni y M. I. Burcet (Eds.) La experiencia musical: investigación, interpretación y prácticas educativas: actas del 13. Encuentro de Ciencias Cognitivas de la Música (pp. 90-105). Sociedad Argentina para las Ciencias Cognitivas de la Música.

Calello, T. (2017). Tango siglo XXI. Una historia del género y el espectáculo en la Argentina. Editorial Biblos.

Carozzi, M. (2015). Aqui se baila el tango: una etnografía de las milongas porteñas. Siglo Veintiuno Editores.

Cecconi, S. (2010, 9 al 10 de diciembre). Los territorios de la milonga en Buenos Aires: Estilo, generación y género [ponencia]. VI Jornadas de Sociología de la UNLP, La Plata.

Cecconi, S. (2018). Resignificación de una cultura local: el tango como territorio turístico. Estudios Sociológicos XXXVI, 36(108), 619-645. 
Cervellera, A. (2019). Centros culturales autogestivos. Producción y reflexión cultural alternativa. Arte e Investigación, 16(34), 1-14.

DeNora, T. (2003). After Adorno. Rethinking Music Sociology. Cambridge University Press.

Estravis Barcalá, J. (2014). El entre-nos de la cultura. Condiciones estructurales y producciones simbólicas en la escena cultural independiente de la Ciudad de Buenos Aires (2008 - 2013) [tesis de maestría]. Universidad Nacional de General Sarmiento.

García Brunelli, O. (2011). El tango actual: estrategias musicales para articular la tradición con un enfoque contemporáneo. Afuera. Estudios de Crítica Cultural, 6(10), 1-9.

García Brunelli, O. (2019). El piazzolismo en las composiciones del tango contemporáneo. Revista del Instituto de Investigación Musicológica "Carlos Vega", 33(1), 179-193.

Gasió, G. (2011). La historia del tango 20: Siglo XXI: década 1. 1. parte. Editorial Corregidor.

Geromet, L. (2011). Buenos Aires Hora Cero Electrónico: un acercamiento a la relación entre la música de Astor Piazzolla y el tango electrónico. Revista del instituto superior de música de la Universidad Nacional del Litoral, 1(13), 111-124.

Gonnet, D. (2017). La construcción de conocimientos pluriversales en la escena del tango de principios de siglo XXI. La experiencia de la Escuela Orlando Goñi. Revista Internacional de Educación Musical, 5 (5), 111-118.

Greco, M., y Cano, R. (2014). Evita, el Che, Gardel y el gol de Victorino: Funciones y significados del sampleo en el tango electrónico. Latin American Music Review, 35(2), 228-259.

Gubner, J. (2014). Tango, Not-For - Export: Participatory Music-Making, Musical Activism, and Visual Ethnomusicology in the Neighborhood Tango Scenes of Buenos Aires [tesis de doctorado]. Universidad de California.

Hennion, A. (2002). La pasión musical. Editorial Paidós.

Jáuregui, J. (2016). Imágenes y solidos del tango en movimiento. Las orquestas en el cine documental. En M. Liska y S. Venegas (Coords.) Tango, ventanas del presente II: de la gesta a la bistoria musical reciente (pp. 57-76). Centro Cultural de la Cooperación Floreal Gorini.

Juárez, C., y Virgili, M. (2012). Contrapunto y enunciación en la Orquesta Típica Fernández Fierro. En M. Liska y S. Venegas (Coords.) Tango, ventanas del presente: Miradas sobre las experiencias musicales contemporáneas (pp. 15-23). Centro Cultural de la Cooperación Floreal Gorini.

Latham, A. (2008). Diccionario enciclopédico de la música. Fondo de Cultura Económica. 
Legislatura de la Ciudad Autónoma de Buenos Aires. (2018, 29 de noviembre). Ley N. 6063. De habilitación y fiscalización para Espacios Culturales Independientes. Boletín oficial.

Lencina, T. (2011). Escritos sobre tango vol. II. Centro 'Feca.

Liska, M. (2003). La escuela de todas las cosas. Tango: acercamiento a los modos de transmisión de la música popular a través de la reconstrucción oral. Editorial del Centro de la Cooperación Floreal Gorini.

Liska, M. (2018). Entre géneros y sexualidades. Tango, baile, cultura popular. Editorial Milena Caserola.

Marcos, G. (2012). El poder del grupo. La alternativa cooperativa de las orquestas típicas. En M. Liska (Coord.) Tango, ventanas del presente: Miradas sobre las experiencias musicales contemporáneas (pp. 119 a 131). Centro Cultural de la Cooperación Floreal Gorini.

Martínez, R., y Molinari, A. (2016). De D'Arienzo a Ferrer. Tango, Sociedad y Política. Editorial de la cultura urbana.

Morel, H. (2009). El giro patrimonial del tango: políticas oficiales, turismo y campeonatos de baile en la ciudad de Buenos Aires. Cuadernos de Antropología Social, 1(30), $155-$ 172.

Morel, H. (2013). Buenos Aires, la meca del tango: procesos de activación, megaeventos culturales, turismo y dilemas en el patrimonio local. PUBLICAR, 6(15), 55-74.

Observatorio de Industrias Culturales de la Ciudad de Buenos Aires. (2007). El tango en la Economía de la Ciudad de Buenos Aires. Subsecretaría de Industrias Culturales del Ministerio de Producción.

Peña, J. (2006). El tango en el Teatro Colón. Marcelo Héctor Oliveri Editor.

Polti, V. (2016). Nuevos Tangos en Buenos Aires. Diálogos intergenéricos, porosidad e identidades compartidas. En M. Liska y S. Venegas (Coords.) Tango, ventanas del presente II: de la gesta a la historia musical reciente (pp. 37-57). Centro Cultural de la Cooperación Floreal Gorini.

Radakovich, R. (2014). El gusto revisitado: distinción, hibridez y omnivoridad en el cono sur latinoamericano. Revista Diálogos Possiveis, 13(2), 187-205.

Salton, R. (2019). Tango en el siglo XXI: ¿presente o pasado? Revista del Instituto de Investigación Musicológica "Carlos Vega", 33(1), 17-28.

Semán, P. (2005). Vida, apogeo y tormentos del rock chabón. Versión, 1(16), 241-255.

Spinella, S. (2012). El mapa teatral porteño. S/n Revista. http://territorioteatral.org.ar/ html.2/articulos/pdf/n9 05.pdf 
Epistemus - volumen 9 - número 1 (Julio de 2021)

DOI: https://doi.org/10.24215/18530494e026

Verdenelli, J. y Orozco, D (2009). El tango en el siglo XXI. Rituales de interacción en las milongas contemporáneas de la Ciudad de Buenos Aires [tesis de licenciatura]. Universidad del Salvador.

Vidal, A. (2007, 4 - 6 de octubre). Neotango [ponencia]. Segundas jornadas del Departamento de Humanidades del Área de Historia del Arte, Buenos Aires, Argentina.

Wortman, A. (2015, 13 - 17 de julio). Impacto de los Centros Culturales autogestionados en la escena cultural independiente de Buenos Aires [ponencia]. XI Jornadas de Sociología de la Facultad de Ciencias Sociales de la Universidad de Buenos Aires, Argentina. 